- Webb Keane

University of Michigan

wkeane@umich.edu

\title{
Indexing Voice: A Morality Tale
}

This reexamination of Hill's "Voices of Don Gabriel" looks at the role of typifications, and conflicts among them, in the process of moral self-formation and even self-discovery. What Hill calls "voices" link evanescent moments of stylistic variation and stance to more stable figures that can be recognized across interactions. My reading of her dialogic approach stresses the productivity of the clash of voices. The concept of voice forms a connection between general aspects of intersubjectivity, detailed features of interaction, and the historical specificity of moral communities. [morality, stance, typification, indexicality, interaction, voice]

\section{Introduction}

$\mathrm{J}$ ane Hill's work demonstrates a rare ability to bring precise linguistic analysis to bear on broad questions of social existence, with a special sensitivity to subtle traces of power and structures of inequality. In this article I will draw on her well known essay, "The Voices of Don Gabriel" (Hill 1995) to explore some of the implications of her analysis for social thought in fields beyond the discipline of linguistic anthropology. Hill's essay is notable for its innovative synthesis of the work of Erving Goffman and M. M. Bakhtin. This synthesis gives substance to a point of convergence that might otherwise remain virtual, which she identifies with the concept of voice. Before turning to Don Gabriel, however, I will discuss the theoretical problem to which, among other things, Hill offers a response. The implications and problems I discuss here should not be taken as self-evident. Although they derive from background assumptions shared by many linguistic anthropologists, since they are not always as evident to colleagues beyond the subfield, this article will begin by sketching them out.

Just what is the pertinence of the close analysis of speech for our understanding of other scales of social life? What bearing does the study of conversation, for instance, have on empirical observations and forms of explanation that are not wholly identifiable within the spatial and temporal boundaries of any single set of interactions? What counts as a satisfactory answer will presume different notions about what is the relevant, and relevance-determining level of analysis and explanation. Presumptive terms of relevance have included concepts of cultural meaning, historical forces, social power and resistance to it, psychodynamics, and human cognition. One tradition focuses on the sui generis nature of linguistic interaction, rejecting the demand that close analysis of conversation be justified with reference to a more encompassing level or scale. Erving Goffman sometimes appears to take this position. The interaction order, he argued, is "a substantive domain in its own right" (1997 [1983]:236). The nature of this domain is such that it is likely to "exhibit some markedly similar features" across societies (1997 [1983]:239); thus those features cannot directly reflect societies at the level at which they vary. But Goffman (at least in his earlier work) drew on Emile Durkheim (1938 [1895]) in ways that suggest important links between

Journal of Linguistic Anthropology, Vol. 21, Issue 2, pp. 166-178, ISSN 1055-1360, EISSN 1548-1395. (C) 2011 by the American Anthropological Association. All rights reserved. DOI: 10.1111/j.1548-1395.2011.01104.x. 
what occurs within that theater within which people are physically present to one another and the social world that extends beyond the immediate here-and-now of interaction.

In Goffman's account, the work of self presentation aims at producing a smooth interaction. The value of smooth interaction derives from the need to successfully project one's own face, to have it accepted by others, and preserve theirs in turn. ${ }^{1}$ To this extent, the level of explanation remains within the interaction order. The need for, or value of, face itself is treated as more or less self-explanatory. Yet Goffman's own writing often hints that the very process of preserving face requires continual reference to another domain of social order. Thus in an early piece he says

By acquiring [universal human nature], the person becomes a kind of construct, built up not from inner psychic propensities but from moral rules that are impressed upon him from without. These rules, when followed, determine the evaluation he will make of himself and of his fellow-participants in the encounter, the distribution of his feelings, and the kinds of practices he will employ to maintain a specified and obligatory kind of ritual equilibrium. The general capacity to be bound by moral rules may well belong to the individual, but the particular set of rules which transforms him into a human being derives from requirements established in the ritual organization of social encounters [1967 [1955]:45]

On the one hand, those "moral rules" contribute to the organization of social encounters, and thus seem to remain within the domain of interaction. On the other hand, the rules include the invocation of social roles and categories that do not, it seems, emerge from within the immediate situation. In this latter respect, they form a vehicle by which society imposes itself upon its members, without their fully realizing it.

The Goffman of these earlier writings often seems to understand that what makes the rules "moral" is the character of their mandate. For the rules of interaction are not merely technical instruments by which communication is effected and individuals coordinated. They are "social" rules, and it is evident that in following them, the individual is both deferring to some kind of consensus and becoming ever more committed to it. The logic is very similar to that of Durkheim's analysis of ritual (1995 [1912]), one of continual reinforcement, producing increasingly heartfelt conformity to a social order that constrains and shapes otherwise fractious individuals. ${ }^{2}$

Hill has been an especially original and creative reader of Goffman, but one whose work points us to quite different understandings of social life. In this article, I want to reflect on and develop some of her insights by looking at her analysis of voice. The first of these insights is that we can gain purchase on large-scale political and social questions by attending to the moral dimensions of speech. The second is that (contrary to some critics of moral thought) attention to morality does not require us to ignore or play down political perspectives. And third, taking those moral dimensions seriously does not commit us to the idea that a moral community must entail a harmonious consensus.

Hill's analysis has persuaded me that the internal clash of voices is a pervasive feature of ordinary interaction and selfhood. Here I want to push her argument further, or perhaps merely make some of its entailments more explicit, as a contribution to the anthropology of morality. The clash of voices is relevant to two central problems for any empirical analysis of moral and ethical life. The first concerns the relation between moral psychology and local social norms. The second concerns the relation between habitual or tacit intuitions and explicit moral injunctions or their rationalizations. "The Voices of Don Gabriel" provides an ethnographic analysis situated at a point in which all of these dimensions are in play, and none completely dominate.

Developing the implications of Hill's analysis, I will argue that learning how to speak certain registers, to take on certain styles, to stage voices, is part of the process of distinctively moral self-formation. If self-consciousness emerges out of social interaction, as Mead (1934) and, in a different tenor, Bakhtin (1981), suggested long ago, so 
too do certain aspects of moral awareness. Here I propose that what Hill calls "voice" results from processes of typification (Agha 2007, Schutz 1967). These processes allow her to identify evanescent details of stylistic variation with enduring social figures that link momentarily apparent features of talk to presupposable evaluative types that can be recognized across interactional contexts. These figures have moral implications by virtue of their role in the play of "stance." If stance sometimes refers to judgments that flit across moments of interaction, when stabilized in typified figures, stance can also involve values whose force is amplified by that reference across contexts which typification facilitates. The clash of voices both draws on existing social figures and can help consolidate them, by sharpening and sometimes stabilizing their distinctions. These processes, I will suggest, can help push a person's tacit moral intuitions to more explicit form. As Hill's account of Don Gabriel shows, however, the result is not necessarily an individual wholly identified with a stable, self-consistent moral center. The analysis of "voice" suggests ways to investigate the bonds between general features of intersubjectivity and the social circulation of moral figures within historically specific communities.

\section{From Verbal Interaction to Morality}

Before turning to Hill's approach, I will sketch a few themes evident in some other approaches to language and morality. ${ }^{3}$ One is that some kind of moral intuition is a condition for the very possibility of verbal interaction. Thus one might postulate that verbal interaction presupposes some underlying commitments that would count as moral primitives. For example, H. P. Grice's (1975) model of conversational pragmatics starts with the "principle of cooperation" that generates maxims such as "be truthful." Grice does not seem to have intended any specifically moral interpretation of the principle of cooperation; it could, for example, be understood merely as a technical device to make communication more efficient. ${ }^{4}$

But the principle implies that people enter into interactions with a default assumption that others should be taken to be cooperative until proven otherwise. As such, it seems to involve mutual orientation to one another and a reciprocity of perspectives (which are required even for ordinary social conflict) that might provide a basis on which a morality of regard for other people could be developed. ${ }^{5}$

Not surprisingly, philosophical attempts such as those of Grice (and we might add Jürgen Habermas, e.g. 1984) have been criticized by anthropologists for relying on assumptions about cooperation, sincerity, and truthfulness that are either highly local in themselves, or require local specification in order to function (Hanks 2002; Keane 1997a; 2002; Keenan 1976; Lee 1992; Rosaldo 1982; Sweetser 1987). Yet they do suggest that even apparently instrumental features of interaction may be inseparable from human propensities to make value judgments on the basis of semiotic forms (e.g. "quantity" of speech) in ways that cannot be reduced to the technical requirements of communication.

Without doing too much violence to his work, we might see Grice as implicitly presupposing this question: what makes it possible for people to enter into interaction with one another, given an initial condition of separateness? By contrast, in a tradition dating back at least to L.S. Vygotsky (1978), studies of the child's socialization to language (e.g.,Ochs 1988; Schieffelin 1990) and of attributions of responsibility (Hill and Irvine, eds. 1992), which do not take separateness to be an initial condition, often reveal more strongly distributive perspectives on interaction. This is evident in those studies that suggest the emergence of a sense of responsibility in the child, and subsequently, any process of imputing responsibility to others, both depend on verbal interaction. The two aspects of this claim-that responsibility depends on something linguistic, and that it is interactive-are logically distinct. The first aspect concerns the role of language itself in specifying just what the action is, and who the agents are, such that responsibility is even in question at all. ${ }^{6}$ As Charles Taylor (1985) has argued, one can only be fully responsible for action as one knows it (at least in the 
dominant western traditions). That is, a precondition for the attribution of responsibility is the establishment of what Goffman called a "definition of the situation" or G. E. M. Anscombe "action under a description" (1957). To say this does not require us to identify "description" with lexically focused reference and denotation; the grammar of modality, for instance, is another resource. But it does bring out the role language may play in defining an event as being the kind of action that is subject to praise and blame. Indeed, this would seem to be a significant component of the social power of metapragmatics (Silverstein 1993).

The second aspect of the claim that responsibility is linked to verbal interaction is exemplified by work that shows how responsibility for an action, or the business of imputing it, can be distributed among several participants in an interaction. This may occur not only in public negotiations, formal accusations, or didactic discourses (Keane 1997b; Merlan and Rumsey 1991; Shoaps 2007), but also the ordinary and ubiquitous flow of conversation (Sacks 1974; Sidnell 2010). And as Goffman's (1981) pioneering work on footing makes clear, the various possible participant roles and kinds of reported speech can be distinguished by the wide range of degrees of identification with, and responsibility taken for, a speaker's "own" spoken words that they facilitate.

Children are socialized not just to adhere to interactive norms but also to the social identities those norms may index, and to which, iconically, those norms may give content. For example, noble rank may be inseparable from certain expectations about rank holders' presumptive participant roles in interactions (Duranti 1994; Errington 1988; Irvine 1974; Ochs and Schieffelin 1984). One might suggest that the virtue attributable to the social category depends on and is manifested in its incumbents living up to certain linguistic expectations. Thus their verbal performances are subject to evaluation that may have moral entailments. The interactive construction of the specific virtue that pertains to a social category, and the vulnerability that results, applies as much to Wolof aristocrats as to the North Americans of whom Goffman said "The divination of moral character by adducing indicators from the past is one of the major preoccupations of everyday life. And the treacherous feature is that "a case can be made," and at the same time there is no foolproof way of determining whether it is made correctly" (1974:453). Indeed, this remark summarizes an important part of the vast literature on deference and demeanor, registers, honorifics, and, in general, the linguistic construction of social identities.

The classic studies of socialization and of deference and demeanor tended to treat the norms in question as more or less given within a particular community. More recently, the focus has shifted to the emergent character of social categories, values, and evaluative stances. Some of this work centers on the process that Alfred Schutz dubbed "typification" (1967), a point to which I return below. First, a note on how the notion of stance can pertain to the linguistics of morality. To the extent that stance is a pervasive feature of verbal interaction, it also exemplifies the ubiquity of evaluation. But to the extent stance is an emergent phenomenon, it follows that evaluation does not necessarily depend on a prior set of stable norms. At the same time, the analysis of stance may provide crucial insight into the processes out of which relatively stable norms may come to be established.

Charles Goodwin (2007:70-1) defines "moral stance" as "action in such a way as to reveal to others that the actor can be trusted to assume the alignments and do the cognitive work required for the appropriate accomplishment of the collaborative tasks they are pursuing in concert with each others [sic], that is to act as a moral member of the community being sustained through the actions currently in progress." Goodwin is situating morality as a very basic, ubiquitous, presupposition of ordinary interaction, the mere expectation that others are cooperative. But the expectations may go beyond those of cooperation and smooth interaction. Paul Kockelman summarizes the recent tendency to see stance as "a way of categorizing and judging experience particular to a group or individual that turns on some notion of the good or true" (2004:129). As he observes, the emphasis here lies on the public, 
intersubjective, and embodied character of evaluation, rather than the private, subjective, and psychological. Notice as well that if stance links "the good or the true" to the experiences of a particular group, it verges on Aristotelian notions of "virtue" (1941).

Recalling the claim that the very fact of interaction may be evidence of underlying moral commitments, we may find the moral dimension of stance to lie not necessarily in evaluation, but simply in its inherently intersubjective nature. In what John Du Bois calls "the stance triangle" (2007) the individual alone does not take a stance, since stance involves simultaneously people's relationships to each other, and to some third entity. Du Bois notes that this parallels the emergence of intersubjectivity described by Tomasello (1999), in which young children align themselves with others with respect to some third object of attention (see note 5). If we identify the reciprocity of perspectives as a precondition for morality, this intersubjectivity, mediated by a fundamentally semiotic structuring of links among persons, interpretants, and objects, may offer an outline of a fundamentally moral dimension of interaction.

According to Du Bois's account of stance, any two subjects align themselves with each other with respect to their respective evaluations of an object, toward which they are also positioning themselves as subjects. Yet the intersubjectivity of stance does not stop there. Since it takes place in time, "the very act of taking a stance becomes fair game to serve as a target for the next speaker's stance" (2007:141). And the game is not always fair, as Judith Irvine (2009) shows, the stance attributed to us on the official record, consolidated over the long-term, is ultimately out of our hands. This is partly a function of the sheer temporality of interaction. But it is also shaped by larger-scale social phenomena such as institutional power, prevailing stereotypes, and even the constraints built into the media of interaction (e.g. face-to-face conversation and writing entail different vulnerabilities to being taken out of context, with different options for correction or revision). At this point, analysis moves from the very general principles of interaction and socialization to the specific political and historical dynamics of typification. A crucial link between the intersubjectivity inherent in any interaction, and the emergence and recognition of moral types, in the form of personae or figures (see Agha 2005) is found in the phenomena grouped under the rubric of "voice."

\section{Don Gabriel's Voices}

At this point I turn to Jane Hill's (1995) account of voice as indexical of inner moral conflict. Hill's analysis is based on a narrative that emerged in the course of a conversation with Don Gabriel, a speaker of the Native American language known as Mexicano, who lived in a subsistence-farming village of central Mexico. Don Gabriel tells of the murder of his adult son nine years previously, the result of envy and suspicions that arose out of the son's position as treasurer of a local bus service. Hill argues that the narrative implicitly stages a contest of value systems. It pits Indianidentified subsistence farmers who are committed to relations of reciprocity among kin and villagers, against the Spanish-oriented world of individualistic urban capitalists.

Virtually none of the moral contest takes explicit propositional form. It emerges under the analysis of linguistic and stylistic variation in Don Gabriel's discourse, including language switching between Mexicano and Spanish, different kinds of dysfluency (false starts, stutters, verbal slips, memory gaps, and so forth), shifts in the use of tenses, and changes in intonation contour. Many of the voices Hill identifies are attributable to protagonists in the narrative. They usually appear as reported speech, clearly marked off from the speech of the narrator. But there are also several distinct voices identified with Don Gabriel himself. In distinction from the portrayal of characters in a story, voice in this sense is inherently evaluative. It not only depicts a moral position, it also situates the speaker in relation to it; that is, voice in this second sense is an act of stance-taking. According to Hill, Don Gabriel embodies by turns a neutral 
narrator, an engaged narrator, an emotionally overcome protagonist (the murder victim's father), and a moral commentator on the events the narrator is portraying. The latter offers his commentary to the listener through direct address, marked by other techniques of immediacy such as historical present verb tenses and certain intonation contours. Hill identifies some voices as closer to the speaker's own moral and emotional center. The latter emerges in the desperate intonation shadow that appears in the voice of the father devastated by the death of his son (1995:132).

If the formal variations in Don Gabriel's speech display his effort to map out a moral terrain and position himself within it, they are also evidence for his lack of full self-mastery. At the lexical level, for example, Don Gabriel uses only Spanish vocabulary when referring to the dealings for profit, as if verbal control over reference could sustain the moral boundaries his community attempts to draw around the world of commerce. Yet even then, he tries to assign this vocabulary to voices at a remove from the moral center of his narrative; when a voice close to that center speaks of finance, it is in euphemisms. According to Hill, although Don Gabriel distributes the Spanish lexicon of profit among those voices most distant from his own moral center, it "remains for him alien, and his struggle with it [is] a principal source of dysfluency in the otherwise eloquent flow of his narrative" (1995:108). Hill quotes Bakhtin (1981:294) to say the words " 'cannot be assimilated into [the] context and [will] fall out of it; it is as if they put themselves in quotation marks against the will of the speaker" " (1995:109). When attempting to render how his son told him he was going to town on business, he finds himself unable to come up with the words at all. We might say that the very limit faced by the speaker's agency registers the moral gravity of the choices he is trying to control.

\section{Dysfluency and Moral Conflict}

Hill's essay is of particular interest for a linguistics of morality because it is influenced by Goffman, whose portrayal of social interaction Alasdair MacIntyre took to exemplify the peculiarly amoral condition of modernity. According to MacIntyre, in Goffman's world "imputations of merit are themselves part of the contrived social reality whose function is to aid or to contain some striving role-playing will. Goffman's is a sociology which by intention deflates the pretensions of appearance to be anything more than appearance" (2007:116). But for Hill's Don Gabriel, moral values are precisely what are in question. Although he is clearly attentive to how he is presenting himself to an interlocutor, the appearances he is trying to manage involve serious moral commitments and the difficulties that their contradictions pose for him. As Hill puts it, he must face that "moral choice required of the speaker among the terministic and linguistic possibilities" available to him (1995:97). The notion here that linguistic choices are distinctly moral is crucial. In Hill's analysis, stylistic variations bear moral implications first, because they are choices among options, and second, those choices index both a cast of social figures who manifest distinct commitments and visions of the good, and the speaker's identification with or estrangement from them. But what grounds that indexicality?

To begin with, the key moments hinge on dysfluencies, which Hill takes to be indexical of points of internal conflict that Don Gabriel cannot resolve or stances he cannot fully master or exclude. Thus dysfluency, in her analysis, is a symptom of underlying trouble that interrupts what would otherwise be a smooth performance. I will follow her lead in this, but first note two qualifications. First, as Irvine (1974) made clear long ago, dysfluency may also be an artful or even wholly conventionalized presentation of self in its own right. Dennis Tedlock (Hill 1995:143, n. 16) and Richard Bauman (personal communication) have suggested Don Gabriel's talk may be a well-honed performance, in which moments like these are a masterful staging of dysfluency. This points to a more general principle, that we not conflate semiotic form directly with psychological state. The latter remains only that which is imputable on the basis of socially recognizable forms (see Agha 1995:144). Second, as Hill's own 
work (e.g.: 1985), and other literature on registers has shown, the knowledge, skill, and authority needed to successfully appropriate a socially marked speech variation are not evenly distributed within a community. Constraints on ability and legitimacy are, of course, part of why a style can be indexical of a social identity. Thus dysfluency can manifest a speaker's lack of social warrants for inhabiting certain figures, one way of answering Gayatri Spivak's question "Can the subaltern speak?" (1988).

Hill offers us an intriguing alternative to some other accounts of the failure of speech in the face of trauma, such as E. Valentine Daniel's (1996) description of semiotic collapse when people recount violent episodes in Sri Lanka's civil war or Veena Das's (2007) analysis of the loss of voice after massacres and rapes in India. In those cases, trauma is supposed to render the victim speechless because of events so extreme as to escape all discursive resources. Don Gabriel's failures are quite different:

The English speaker imagines that the great problem for such a narrator might be to come to grips with the horror of the violent death of a child. However, passages having to do with the death are among the most artful and fluent in the narrative.... Don Gabriel can speak the death of the child. What resists his voice and "falls out" of his fluent narrative art is the language of business and profit. [1995:137-8]

This is not the willful and amoral self that MacIntyre ascribes to Goffman's world. If it is not the sovereign subject of liberal traditions (see also Hill and Zepeda 1992), neither is it the interpellated, disciplined, nor even performative subject of poststructuralist thought. To the extent Don Gabriel has trouble controlling the voices he utters, his talk resembles that of a spirit medium, who is possessed by a spirit but does not thereby surrender complete control to it. Possession is a struggle in which the medium always has a say. Perhaps the relation between a moral community and those who are part of it can be thought of in similar terms. Don Gabriel's encounter with the moral universe is neither created tabula rasa nor scripted in advance, but draws on the raw materials at hand. His words are not simply vehicles for expressing a self that stands wholly independent of them, for it seems his self-knowledge depends upon those very voices.

According to Hill, variations in verbal form offer clues to two things, the presence of multiple voices in the narrative, and a struggle for dominance among those voices and the moral positions they index. In choosing a stylistic option, Don Gabriel is not simply trying to present a pleasing appearance to an interlocutor, or to make the interaction run smoothly. Rather, the presentation of self is a kind of moral work on the self. Indeed, to speculate beyond the analysis Hill gives us, it may be that the objectification of moral possibilities, through such means as staging different voices, plays a critical role in the development of self-knowledge. This may constitute a discovery process by which the speaker comes to realize which moral figures he will become committed to.

But because the discursive resources on which the speaker draws are inherently dialogic in two senses - they both juxtapose social possibilities, and are addressed to other voices-work on the self cannot easily be a single-minded process. According to Hill, Don Gabriel tries to establish a coherent moral position among conflicting ways of speaking, weighted with contradictory ideologies, by distributing them. For example, he cannot simply eliminate the presence of the voices of the profit-seekersamong other things, he would be unable to account for his own son's actions-but he can locate them as far as possible from the voices most closely identified with himself. Yet these voices continue to interrupt his efforts at control. For just as he participates in a social world that includes profit-seeking, and is not a wholly monolithic moral actor as the idealized portrayal of the egalitarian farmer would have it, so too the voices that index that world remain part of his own discursive repertoire, and cannot be entirely silenced.

More than a contingent matter, it appears that the struggle for dominance among the voices manifests a condition endemic to social existence. Don Gabriel cannot help 
but straddle the polarization between the communal values of the Mexicano peasant and the self-interested, profit-seeking actions of the urban Spanish-speaker. The moral communities his voices index are not isomorphic with socially bounded groups. Even a community as small and tradition-oriented as Don Gabriel's is internally riven, and individuals can find themselves moving among the options, crystallizing the voices that circulate in their social universe. Don Gabriel's dysfluencies may exemplify something ubiquitous about the ordinary morality of everyday life.

Given the linguistic, ethnic, and class conflict that marks Don Gabriel's world, it is appropriate that Hill draws on Mikhail Bakhtin, whose dialogic portrayal of language evokes a much more socially and politically embroiled world than do the more local struggles within Goffman's dramaturgy. Developing Bakhtin's notion that voices are fundamentally evaluative, Hill focuses on them as means by which speakers chose among the moral possibilities at play within a community. Bakhtin sees even smallscale social life as a matter of struggle among distinct ideological and normative positions, noting that

an illiterate peasant, miles away from any urban center, ... nevertheless lived in several language systems: he prayed to God in one language (Church Slavonic), sang songs in another, spoke to his family in a third, and when he began to dictate petitions to the local authorities through a scribe, he tried speaking yet a fourth language. [Bakhtin 1981:295-296].

It follows that linguistic, social, or cultural unity, is an artificial imposition. For any given member of a community, the usual condition is to align oneself with some positions and challenge others. This is a matter both of social or political affiliation and also of orientation to morally exemplary speakers metapragmatically identifiable with certain speech styles. At the most pervasive level of everyday life, this takes place through the play of voices. But Bakhtin's observation goes beyond the truism that communities are internally conflicted, for the play of voices does not merely take place among individuals. It also occurs within the speech of an individual. This internal play of voices is something that purifiers have sought to eliminate in the name of everything from national language ideologies (Bauman and Briggs 2003) to norms of personal sincerity (Keane 1997a, 2002). That is, some political and philosophical traditions might take the very existence of internal conflict among voices to be a moral failing in itself; Hill's approach suggests something quite different.

\section{Typification, Indexicality, and Voice}

Hill's analysis of Don Gabriel's narrative focuses on internal dialogism. But of course his narrative takes place within an interaction, albeit one in which he holds the floor for an extended turn of talk. Thus this account could usefully be complemented with a parallel analysis of external dialogism, such as how Don Gabriel is seeking to align himself with or against his interlocutor (and, one suspects, non-present critics), the interlocutor's corresponding alignments, and the moral recognition they might involve. For there seems to be a triple dialogue, that among Don Gabriel's own voices, that between Don Gabriel and his immediate interlocutor, and that with absent interlocutors.

Hill herself provides examples of this interactive dimension elsewhere. In "The Grammar of Consciousness" (Hill 1985) shows the power certain members of the community can exert in recognizing or denying recognition to other speakers' implicit moral claims-making by pointing to their purported failure to master the language itself. In Don Gabriel's case, we can surmise that his deployment of voices arises in part as an effort to gain recognition from his interlocutor as being a good person, and perhaps as well that he is making some kind of moral claim on that interlocutor. At the very least, this would include asking the latter for collusion in the construction of Don Gabriel's own self image (bearing in mind that Don Gabriel may himself be a crucial audience for his own moral performance). One does not just stage 
a moral figure for no reason at all. In verbal interaction, voices call for a response of some sort, an affirmation, for example, or cooperation in consolidating or gaining recognition for the position being voiced.

For this to work, however, stylistic variations must be recognizable to the interlocutor as voices. That is, they must be construed as indexical of an identifiable figure. But any given formal features of speech cannot be inherently indexical of anything in particular. Indexicality is always underdetermined for reference and denotation without some means of specifying just what, exactly, is being indexed (Hanks 1992). Thus the identification of stylistic features is both labile over the course of interaction, and demands interpretation. The interpretive ability to establish just what is being indexed is crucial to Hill's central insight, that Don Gabriel's voices point to possible worldviews, and stage evaluative stances toward them. This is why any verbal difficulties may have implications that go beyond interaction, for small indications of trouble might manifest conflict between entire moral communities. Therefore, the argument linking stylistic variation to moral conflict hinges crucially on our analysis of indexicality, social typification, and speaker identifications with voiced personae (Agha 2007, Silverstein 2003).

As a more general principle, we might say that the indexicality which allows one to identify the formal features of a stretch of discourse as a voice depends on a potential or postulated resemblance involving some more durable or systematized imagery, such as habitus (Bourdieu 1984). That is, it requires some iconicity that allows one to identify the discourse as a voice by virtue of that voice being recognizable as a generalizable figure of a certain type. The moral figure, as a type, is thus repeatable and capable of circulating across-and being subject to authoritative shaping within-distinct contexts. Once a certain way of speaking begins to circulate across contexts and unite (to be recognizable across) different moments of interaction in such a way as to produce the effect of a person having a certain knowable character, of a certain moral inflection and socially identifiable nature, then it takes on the full-fledged nature of a social figure or stereotype (Agha 2007).

If Hill is right, Don Gabriel's voices index value systems that pre-exist his invocation of them: they are not purely emergent in the moment of speaking. On the other hand, by giving voice to moral values he is contributing to the figurations that make them invocable. If Don Gabriel's narrative is in fact a well-honed performance, as suggested above, then repeating his stylistic choices may further help consolidate the moral figures they manifest, making them more recognizable to his interlocutors. By disambiguating and stabilizing the indexical ties between style and figure, voices become, at least potentially, all the more available for appropriation and circulation by other speakers. In full-fledged form, variation in speech is consolidated into a style, the range of actual social experiences is consolidated into kinds of people, and the speech style and social type are taken to be naturally bound together. Thus Don Gabriel's speech manifests the dynamic of typification.

As is common, indexicality in this case works in conjunction with iconicity to provide it with substance: thus the appearance of the Spanish lexicon in Don Gabriel's discourse is both indexical and iconic of the figure of a person oriented to capitalist values. Voice thus forms a bridge from the scale of immediate verbal interaction to that of widely shared stereotypes and values that persist across interactions, because for it to work as an indexical icon it must be recognizable with reference to some publicly circulating figures or their emergent possibilities. At the same time, those public figures only exist to the extent they are staged in concrete interactions. Typification refers to the ways in which this moment-by-moment emergence comes to be consolidated, for example in figures that have larger time scales in social circulation, such that they do not vanish at the end of a given interaction.

Fully realized or only fleetingly apparent, such figures underwrite the evaluative power of stylistic choices available to any speaker. The voice is the palpable objectification of the figure that has the potential to upshift judgments from momentary to more durable form. To the extent that staging a voice is a mode of stance-taking, and 
thus involves judgments or evaluations, the stylistics of voice contribute to the public circulation of knowable moral figures. As Bakhtin suggests, the need to choose among the options available in the public space within which the voices circulate is itself crucial to the production of consciousness (1981:295). A fully self-aware moral actor would thus seem to depend on the existence of differing, or even conflicting voices, and upon the possibility of moving among the different options afforded by semiotic form. To the extent that the self is drawing on voices or the materials for potential voices in the surround, it may be discovering something about itself and its social context through its encounter with the figures those voices embody.

The interactive order is a major site where this process of self-discovery transpires, but neither its resources nor effects can be confined to the moment of interaction in isolation. Interaction contributes to typification, but also draws on the past typifications-concretized in persistent bodily habits, familiar linguistic forms, and so forth, detached from the interactive contexts out of which they emerged. As voices, typifications offer up objectifications that require uptake and potential recontextualization by other participants in order to become recognizable categories and stereotypes identifiable as indexing something about "what is going on here, " and "who is doing it to or with whom" - and why these matter, something mere categorization fails reveal. Hill's analysis of Don Gabriel's voices shows us emergent typifications caught on the fly. But at the same time, Don Gabriel himself may also be learning to find his way amidst the moral possibilities and their political consequences entailed by typifications with which he is already familiar. Typifications, seen in this light, are simultaneously ready-to-hand vehicles for indicating stance, and media for the emergent objectification of moral values that contribute to the subjectification of those whose actions index them.

\section{Acknowledgements}

This essay has benefited from comments by Richard Bauman, Adela Pinch, Elinor Ochs and members of the UCLA Center for Language, Interaction, and Culture, anonymous reviewers for the journal, and especially Judith Irvine. My thanks to the editors and to Jane Hill for her beneficent spirit. Parts of this essay appear in somewhat different form in Keane 2010.

\section{Notes}

1. As Asif Agha (1995) points out, Goffman's early work was influenced by a rather individualistic reading of George Herbert Mead (1934), since moral rules impress themselves on a strategizing self. Agha observes that this makes unintended communication something of a problem, which Goffman's later turn to more phenomenological and language-oriented approaches attempted to resolve.

2. I stress this influence in the context of this article not because I want to reduce Goffman to some kind of Durkheimian, but because the centrality of morality to Durkheim's understanding of the problems that motivate social thought helps reveal an aspect of Goffman that has not always seemed obvious to his readers.

3. Here I treat "moral" as a cover term for evaluation with respect to some notion of the good or virtuous, subsuming ethics (but see Keane 2010 for some distinctions among these concepts).

4. Cooperation, at any rate, should not be confused with helpfulness: it may mean just shared orientation, for instance, agreement about what kind of activity is taking place. But, as one anonymous reviewer of this article notes, even apparently bare functionalism tends to presume utilitarian moral philosophy.

5. Emile Benveniste (1971; see Hill and Irvine 1992:13-14) argued that the reciprocity of perspectives on which social interaction is grounded, derives from the mastery of the first and second person pronouns. Alan Rumsey $(2003,2010)$, drawing on Tomasello (1999) and other developmental psychologists, has criticized this on the grounds that the ontogenic development of verbal interaction itself depends on a pre-linguistic cognitive capacity for reciprocity of perspectives and alignment with others that presupposes a "Theory of Mind." Prior to the use 
of pronouns, reciprocity of perspectives is already evident in the child's ability to point and direct her gaze in parallel to others. That is, intersubjectivity is implicit in such basic semiotic phenomena as indexicality.

6. As William Hanks (1992) has argued, the very deployment of spatial, temporal, and person deixis already plays a fundamental role in defining the range of social copresence or exclusion in terms of which certain interactive moves are relevant or not, an observation that may also have moral implications.

7. This does not mean that figures are necessarily stable, but just that iconicity can function socially only if it contributes to or can otherwise be brought into relation to an imaginary that has the potential to be recognized across instances.

\section{References}

Agha, Asif.

1995 Process and Personality. Semiotica 107(1/2):125-146.

2005 Voice, Footing, Enregisterment. Journal of Linguistic Anthropology. 15(1):38-59.

2007 Language and Social Relations. Cambridge: Cambridge University Press.

Anscombe, G. E. M.

1957 Intention. Oxford: Blackwell.

Aristotle

1941 Ethica Nicomachea. W. D. Ross, trans. In The Basic Works of Aristotle. Richard McKeon, ed. New York: Random House.

Bakhtin, Mikhail M.

1981 The Dialogic Imagination. Caryl Emerson and Michael Holquist, trans. Austin: University of Texas Press.

Bauman, Richard, and Charles L. Briggs

2003 Voices of Modernity: Language Ideologies and the Politics of Inequality. Cambridge: Cambridge University Press.

Benveniste, Emile

1971 (1955) Subjectivity in Language. In Problems in General Linguistics. Mary Elizabeth Meek, trans. Pp. 223-230. Coral Gables: University of Miami Press.

Bourdieu, Pierre

1984 (1979) Distinction: A Social Critique of the Judgment of Taste. Richard Nice, trans. Cambridge, MA: Harvard University Press.

Daniel, E. Valentine

1996 Charred Lullabies: Chapters in an Anthropography of Violence. Princeton: Princeton University Press.

Das, Veena

2007 Life and Words: Violence and the Descent into the Ordinary. Berkeley: University of California Press.

Du Bois, John W.

2007 The Stance Triangle. In Stancetaking in Discourse. Robert Englebretson, ed. Pp. 139-182. New York: John Benjamins.

Duranti, Alessandro

1994 From Grammar to Politics: Linguistic Anthropology in a Western Samoan Village. Berkeley: University of California Press.

Durkheim, Emile

1938 (1895) The Rules of the Sociological Method. Sarah A. Solovay and John H. Mueller, trans, George E. G. Catlin, ed. New York: The Free Press.

1995 (1912) The Elementary Forms of Religious Life. Karen E. Fields, trans. New York: The Free Press.

Errington, J. Joseph

1988 Structure and Style in Javanese: A Semiotic View of Linguistic Etiquette. Philadelphia: University of Pennsylvania Press.

Goffman, Erving

1967 (1955) On Face-Work. In Interaction Ritual: Essays on Face-to-Face Behavior. Pp. 5-45. Garden City: Anchor Books.

1974 Frame Analysis: An Essay on the Organization of Experience. Cambridge, MA: Harvard University Press.

1981 (1979) Footing. In Forms of Talk. Pp. 124-159. Philadelphia: University of Pennsylvania Press. 
1997 (1983) The Interaction Order. In The Goffman Reader. Charles Lemert and Ann Branaman, eds. Pp. 233-261. Malden, MA: Blackwell.

Goodwin, Charles

2007 Participation, Stance and Affect in the Organization of Activities. Discourse \& Society. 18(1):53-73.

Grice, H. P.

1975 Logic and Conversation. In Syntax and Semantics. Vol. 3, Speech Acts. Peter Cole and Jerry L. Morgan, eds. Pp. 41-58. New York: Academic Press.

Habermas, Jürgen

1984 (1981) The Theory of Communicative Action, Volume One, Reason and the Rationalization of Society. Thomas McCarthy, trans. Boston: Beacon Hill.

Hanks, William F.

1992 The Indexical Ground of Deictic Reference. In Rethinking Context: Language as an Interactive Phenomenon. Alessandro Duranti and Charles Goodwin, eds. Pp. 43-76. Cambridge: Cambridge University Press.

2002 Exemplary Natives and What They Know. In Paul Grice's Heritage. Giovanna Cosenza, ed. Pp. 207-234. Turnhout: BREPOLS.

Hill, Jane H.

1985 The Grammar of Consciousness and the Consciousness of Grammar. American Ethnologist. 12(4):725-737.

1995 The Voices of Don Gabriel: Responsibility and Self in a Modern Mexicano Narrative. In The Dialogic Emergence of Culture. Dennis Tedlock and Bruce Mannheim, eds. Pp. 97-147. Urbana: University of Illinois Press.

Hill, Jane $\mathrm{H}$. and Judith Irvine

1992 Introduction. In Responsibility and Evidence in Oral Discourse. Pp. 1-23. Cambridge: Cambridge University Press.

Hill, Jane H. and Judith Irvine, eds.

1992 Responsibility and Evidence in Oral Discourse. Cambridge: Cambridge University Press.

Hill, Jane H. and Ofelia Zepeda

1992 Mrs. Patricio's Trouble: The Distribution of Responsibility in an Account of Personal Experience. In Responsibility and Evidence in Oral Discourse. Jane H. Hill and Judith Irvine, eds. Pp. 197-225. Cambridge: Cambridge University Press.

Keenan, Elinor Ochs

1976. The universality of conversational postulates. Language in Society. 5:67-80.

Irvine, Judith T.

1974 Strategies of Status Manipulation in the Wolof Greeting. In Explorations in the Ethnography of Speaking. Richard Bauman and Joel Sherzer, eds. Pp. 167-191. London: Cambridge University Press.

2009 Stance in a Colonial Encounter: How Mr. Taylor Lost His Footing. In Stance: Sociolinguistic Perspectives. Alexandra Jaffe, ed. Pp. 53-71. New York: Oxford University Press.

Keane, Webb

1997a From Fetishism to Sincerity: Agency, the Speaking Subject, and their Historicity in the Context of Religious Conversion. Comparative Studies in Society and History. 39(4):674693.

1997b Signs of Recognition: Powers and Hazards of Representation in an Indonesian Society. Berkeley: Cambridge University Press.

2002 Sincerity, Modernity, and the Protestants. Cultural Anthropology. 17(1):65-92.

2010 Minds, Surfaces, and Reasons in the Anthropology of Ethics. In Ordinary Ethics. Michael Lambek, ed. Pp. 64-83. New York: Fordham.

Kockelman, Paul

2004 Stance and Subjectivity. Journal of Linguistic Anthropology. 14(2):127-150.

Lee, Benjamin

1992 Textuality, Mediation, and Public Discourse. In Habermas and the Public Sphere. Craig Calhoun, ed. Pp. 402-418. Cambridge, MA: MIT Press.

MacIntyre, Alasdair

2007 (1981) After Virtue: A Study in Moral Theory. Notre Dame: University of Notre Dame Press.

Mead, George Herbert

1934 Mind, Self, and Society. From the Standpoint of a Social Behaviorist. Chicago: University of Chicago Press. 
Merlan, Francesca, and Alan Rumsey

1991 Ku Waru: Language and Segmentary Politics in the Western Nebilyar Valley, Papua New Guinea. Cambridge: Cambridge University Press.

Ochs, Elinor

1988 Culture and Language Development: Language Acquisition and Language Socialization in a Samoan Village. Cambridge: Cambridge University Press.

Ochs, Elinor, and Bambi Schieffelin

1984 Language acquisition and socialization: Three developmental stories and their implications. In Culture Theory: Essays on Mind, Self, and Emotion. Richard Shweder and Robert LeVine, eds. Pp. 276-320. Cambridge: Cambridge University Press.

Rosaldo, Michelle Z.

1982 The Things We Do with Words: Ilongot Speech Acts and Speech Act Theory in Philosophy. Language in Society. 1:203-237.

Rumsey, Alan

2003 Language, Desire, and the Ontogenesis of Intersubjectivity. Language and Communication. 23:169-187.

2010 Ethics, Language, and Human Sociality. In Ordinary Ethics. Michael Lambek, ed. Pp. 105-122. New York: Fordham.

Sacks, Harvey

1974 The Analysis of the Course of a Joke's Telling in Conversation. In Explorations in the Ethnography of Speaking. Richard Bauman and Joel Sherzer, eds. Pp. 337-353. London: Cambridge University Press.

Schieffelin, Bambi

1990 The Give and Take of Everyday Life: Language Socialization of Kaluli Children. Cambridge: Cambridge University Press.

Schutz, Alfred

1967 (1932) The Phenomenology of the Social World. George Walsh and Frederick Lehnert, trans. Evanston: Northwestern University Press.

Shoaps, Robin

2007 Moral Irony: Modal Particles, Moral Persons and Indirect Stance-Taking in Sakapultek Discourse. Pragmatics 17(2):297-335.

Sidnell, Jack

2010 The Ordinary Ethics of Everyday Talk. In Ordinary Ethics. Michael Lambek, ed. Pp. 123-139. New York: Fordham.

Silverstein, Michael

1993 Metapragmatic Discourse and Metapragmatic Function. In Reflexive language: Reported Speech and Metapragmatics. John A. Lucy, ed. Pp. 33-58. Cambridge: Cambridge University Press.

2003 Indexical Order and the Dialectics of Sociolinguistic Life. Language and Communication. 23(3-4):193-229.

Spivak, Gayatri Chakravorty

1988 Can the Subaltern Speak? In Marxism and the Interpretation of Culture. Cary Nelson and Lawrence Grossman, eds. Pp. 271-313. Urbana: University of Illinois Press.

Sweetser, Eve

1987 The Definition of Lie: An Examination of the Folk Models Underlying a Semantic Prototype. In Cultural Models in Language and Thought. Dorothy Holland and Naomi Quinn, eds. Pp. 43-66. Cambridge: Cambridge University Press.

Taylor, Charles

1985 What is Human Agency? In Human Action and Human Agency: Philosophical Papers I. Pp. 15-44. Cambridge: Cambridge University Press.

Tomasello, Michael

1999 The Cultural Origins of Human Cognition. Cambridge, MA: Harvard University Press. Vygotsky, L. S.

1978 Mind in Society: The Development of Higher Psychological Processes. Michael Cole, Vera John-Steiner, Sylvia Scribner, and Ellen Souberman, eds. Cambridge, MA: Harvard University Press. 